\title{
An Experimental Study of Fly height by Load/Unload in Magnetic Recording
}

\author{
Nuttapat Weerathanakiat, and Pitikhate Sooraksa
}

\begin{abstract}
An experiment study of fly height was performed to observe how the head-disk spacing after loading-unloading the head from the ramp onto the disk on the spin-stand testing. The fly height of write and read operation were analyzed by calculated from the power applied. The heater resistance of write and read were collected during test. Results of the test 190,000 cycles of loading/unloading showed, the fly height of write increased more than the read. The fly height of all heads showed increasing trend. Observing the lube pick up on head and accumulation lube on the disk about $20 \%$. The heater resistance of write and read were quite standing.
\end{abstract}

Keywords - Load/unload, friction sensor, Fly height, Clearance, Heater

\section{INTRODUCTION}

$\mathrm{T}$ HE magnetic recording density in hard disk drives is growing rapidly in a day and it will continue to increase astonishing in response to the demand of the customer. Now a day, the data storage is relevant in a daily life especially the cloud storage which need more capacity. The spacing between read-write head and the disk which is magnetic layer must be reduced to achieve higher signal to noise ratio. Lower flying height increase chance for the head and the disk interaction. Many researchers try to find the new technology to achieve higher capacity. The load/unload technology is also create the higher storage capacity as the physically parking the heads off the disk surface and very smooth recording media is enabled. Smoother disk surfaces allow for closer head fly heights, contributing to improved signal to noise ratio during read and write operations. To reduce the track and bit densities on the recording media combined with load/unload technology made possible to increase the areal density.

Load/unload technology is a viable alternative to contact Start-Stop(CSS) which wear durability benefits proven in hard disk drives. It can improve reliability due to eliminate stiction, longer fly lifetime, greater shock resistance and lower heat dissipation. Including increased areal density from thinner overcoats that mean smoother disk can get lower fly height and reduces power consumption[1]. The head gimbal assembly of load/unload technology, a lift tap extending from

Nuttapat Weerathanakiat, Department of Advance Mechanical HDI of Seagate Technology Thailand, College of Data Storage Technology and Application, King Mongkut's Institute of Technology Ladkrabang, Bangkok Thailand.

Pitikhate Sooraksa, Department of Information Engineering Faculty of Engineering, , King Mongkut's Institute of Technology Ladkrabang, Bangkok Thailand. the suspension for parking on the ramp. Unloading, the ramps lift the heads from the disk surfaces as the actuator moves to the parking position as fig. 1 .

The advantages and disadvantages of load/unload technology are present together, many researchers have studied on load/unload system. Levi et al. [2] performed experiments to study the effects of the ramp profile and the spindle speed on head-disk. Yonghyun et al. [3] presented effect of mechanical parameters for loading contact and instability in HDD, how the height differences cause the loading contact and instability through the relation among mechanical parameter height of the HSA, the ramp and the disk. Tambe et al. [4] studied the effect of various design parameters related to the $\mathrm{L} / \mathrm{UL}$ motions including the $\mathrm{L} / \mathrm{UL}$ speed, ramp height, friction/stiction, and so on. In particular, the effects of the ramp height and a role of slider-suspension design on the L/UL performance were reported. [5]-[8] also study on load/unload technology.

The goal of this work is to observe the flyability from load/unload testing and head-disk interaction.

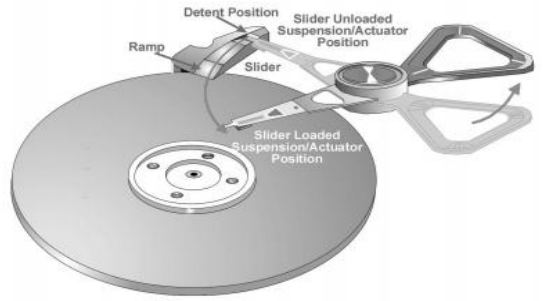

Fig. 1 Ramp load/unload dynamics (From http://www.hgst.com)

\section{EXPERIMENTAL SETUP}

\section{A. Apparatus}

This experiment was performed on spin-stand tester that is design for mechanical testing of head gimbal assembly (HGA) and commercially available. The disk and the head gimbal assembly were installed on the spin-stand of the tester. The experiment setup as schematic presented fig.2 The tester consists of a spindle, an actuator, a arm which hold the HGA and load/unload ramp. A friction sensor is integrated on the arm using for detect contact between the head and the disk. The motor controller drives a spindle and actuator. The circuit board to control the bias voltage to the head. The electronic analog and digital features to process the signal from friction sensor and collect the data. The environmental condition of this experiment is room temperature. 


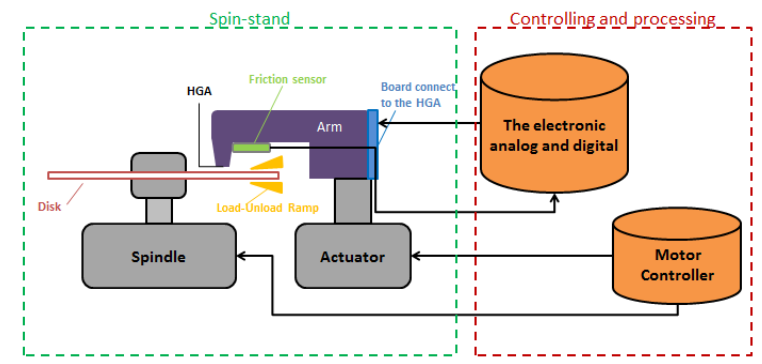

Fig. 2 Schematic cartoon of the experiment setup

\section{B. Samples}

The samples are perpendicular magnetic recording (PMR) 5 heads in a form of head gimbal assembly (HGA). The disk size of 2.5 inch diameter was used. The reader is a tunnel magnetoresistive (TMR) sensor which has the heater for both read and write element. The speed of spinning disk is $5400 \mathrm{rpm}$.

\section{C.Test Method}

The load/unload testing flow shown in figure 3 and the radius zone on the disk as fig.4. Setup tester require to install the head on the arm and the disk on the spindle. The test starts by spinning up the disk then loading the HGA by actuator move to the radius A to measure the fly height. Then is the load/unload cycle test by move between ramp and the radius " $B$ " for 100 cycles, next move to radius " $A$ " to measure the fly height . After that the software is count the load/unload cycles until 190,000 cycles. The head will move to measure the fly height for every 100 load/unload cycles.

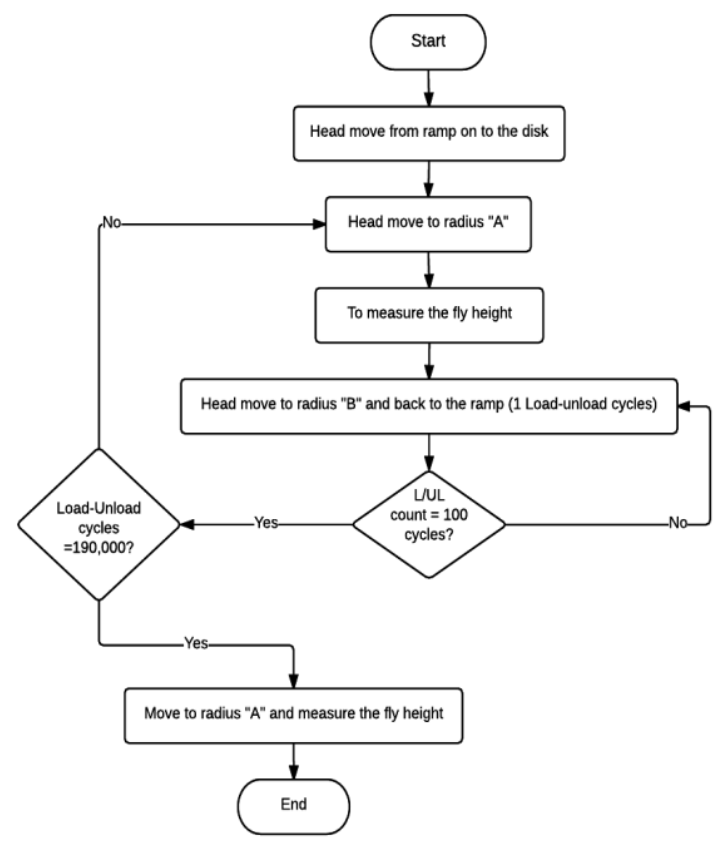

Fig. 3 Load/unload testing flow

For the measurement, the software collected the power data $(\mathrm{mW})$ which is the bias voltage to the heater of head until the friction sensor declared head-disk contacting. The fly heights are calculated by the power that the head use for contact the disk. The recording heads structure, the heater embed by separate heating element for write/read element. The heater structures used for protrusion control of $\mathrm{read} / \mathrm{write}$ element during read and write operation by supply the current to the heater. The fly height measurement of this experiment supplied both heater, the heater of write first, then the heater of read to do the contact power. The head contact disk declared by friction sensor.

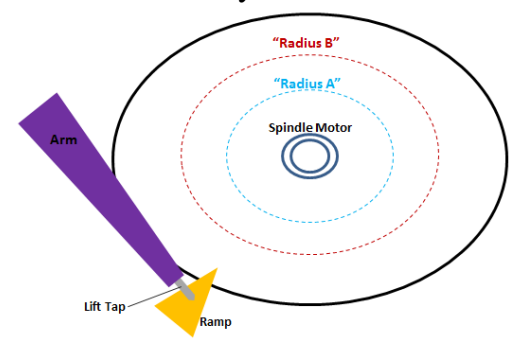

Fig. 4 The radius on the disk for testing; radius "A" for measurement and radius "B" for load/unload.

\section{RESUlTS AND CONCLUSION}

The software collected the heater resistance of write/read, the voltage, current and power for head contact to the disk. The data to analyze by converting the contact power data to the distance between head-media which the $\mathrm{mW}$ to angstrom unit. The fly height calculation using the contact power data and model coefficient as the equation (1)-(3). Observed how the fly heights changed for write/read heater during load/unload test and the resistance of both heater also. After the load/unload testing, taking the head images on the air bearing surface using the microscope and inspection the disk surface by Candela system instrument.

$$
\text { Clearance }=\text { Fly height }-\left(C_{1} P_{c, F r c}\right)+\left(C_{2} P_{c, F r c}^{2}\right)
$$

Assumed head contact the disc, so clearance is zero.

$$
\begin{gathered}
0=\text { Fly height }-\left(C_{1} P_{c, F r c}\right)+\left(C_{2} P_{c, F r c}^{2}\right) \\
\text { Fly height }=\left(C_{1} P_{c, F r c}\right)-\left(C_{2} P_{c, F r c}^{2}\right)
\end{gathered}
$$

$\mathrm{C}_{1}$ and $\mathrm{C}_{2}$ are coefficient. $\mathrm{P}_{\mathrm{c}, \mathrm{Frc}}$ is the apply power to heater that make contact by friction sensor.

\section{A. Fly Height}

The plot of fig.5 showed the fly height changing for both write and read. The fly height of write changed more than the read. Almost fly height changing of write/read showed increase trend from an initial. Hd\#2 was changed the most by increasing about $9.6 \mathrm{~A}^{\circ}$ for write, but the read is increase about $3 \mathrm{~A}^{\circ}$. Fly height of only one head is decrease about $4 \mathrm{~A}^{\circ}$ for write and $1.52 \mathrm{~A}^{\circ}$ for read. The fly height changed of write more sensitive than read.

\section{B. Resistance}

The reader Heater's resistance shows minimal or no changed for all heads although at last cycle test. HD\#2 showed resistance change the most about $6 \mathrm{ohms}$ which the fly height of write changed the most. The heater of write for the rest heads were changed less than 2 ohms. 


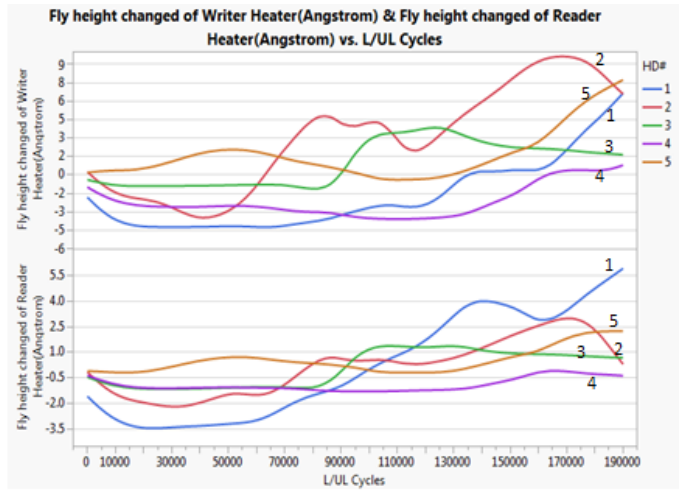

Fig. 5 Plot of fly height changed by heater of write and read versus load/unload cycles.

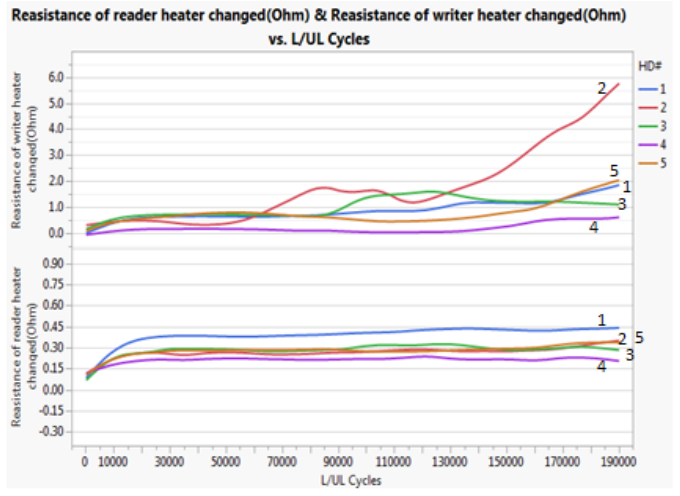

Fig. 6 Plot of writer/reader heater resistance versus load/unload cycles.

TABLE I

RESULT OF EXPERIMENT

\begin{tabular}{|c|c|c|c|c|c|c|}
\hline \multirow[t]{2}{*}{ HD\# } & \multicolumn{2}{|c|}{$\begin{array}{l}\text { Writer Fly height } \\
\text { Maximum } \\
\text { changed }\end{array}$} & \multicolumn{2}{|c|}{$\begin{array}{l}\text { Reader Fly height } \\
\text { Maximum } \\
\text { changed }\end{array}$} & \multirow{2}{*}{$\begin{array}{l}\text { Head } \\
\text { Failure } \\
\text { on Air } \\
\text { Bearing } \\
\text { Surface } \\
\end{array}$} & \multirow[t]{2}{*}{ Disk } \\
\hline & $\mathrm{A}^{\circ}$ & @ Cycle & $\mathrm{A}^{\circ}$ & @ Cycle & & \\
\hline 1 & 7.47 & 189900 & 6.1 & 189700 & Clean & Clean \\
\hline 2 & 9.63 & 167000 & 3.03 & 171200 & Clean & Clean \\
\hline 3 & 4.68 & 125400 & 1.62 & 130100 & Clean & Clean \\
\hline 4 & -4 & 108200 & -1.52 & 84700 & Clean & Clean \\
\hline 5 & 7.72 & 190000 & 2.23 & 184100 & $\begin{array}{l}\text { Lube } \\
\text { pick up } \\
\text { lightly }\end{array}$ & $\begin{array}{l}\text { Lube } \\
\text { accumulation }\end{array}$ \\
\hline
\end{tabular}

$\mathrm{A}^{\circ}=$ angstrom,

\section{Lube pick up on heads and the disk}

Base on microscope inspection failure on air bearing surface. Most of the heads were quite clean, no material/lube picks up on air bearing surface. Only one head lube pick up lightly on surface.

Overall most disks were clean. Except, one disk has lube accumulate about $2 \mathrm{~A}^{\circ}$ at radius " $\mathrm{A}$ " which use for measurement. The summaries of experiment results are clarify in table I that showed the maximum changing for each head.

\section{ACKNOWLEDGMENT}

This study was supported by the laboratory of Mechanical development Verification Test, Seagate Technology at Thailand. The author would like to thank the laboratory guy for support test operation. N.Weerathanakiat's study at the King Mongkut's Institute of Technology Ladkrabang at Thailand was supported by Seagate Technology and NSTDA Thailand scholarship.

\section{REFERENCES}

[1] T. R. Albrecht, "Load/Unload Technology for Disk Drives," IEEE Trans Magnetics., vol. 35, Mar. 1999, pp. 857 - 862 http://dx.doi.org/10.1109/20.753798

[2] P. G. Levi and F. E. Talke, "Effect of ramp profile and spindle speed on head-disk contact during rotary load/unload," IEEE Trans. Magn., vol. 29, no. 6, pp. 3918-3920, 1993. http://dx.doi.org/10.1109/20.281342

[3] Lee, Y.; Hong, E.-J.; Kim, C.-S.,"Effect of Mechanical Parameters for Loading Contact and Instability in HDD", IEEE. Trans Magnetics., vol. 49, pp. 2686 - 2692, 2013. http://dx.doi.org/10.1109/TMAG.2013.2256775

[4] N. S. Tambe and B. Bhushan, "Effect of load/unload process on friction/ stiction and durability of head-disk interface," Microsyst. Technol., vol. 8, pp. 409-418, 2002. http://dx.doi.org/10.1007/s00542-002-0248-9

[5] Q. H. Zeng and D. B. Bogy, "Effects of certain design parameters on load/unload performance," IEEE Trans. Magnetics., vol. 36, no. 1, pp. 140-147, 2000. http://dx.doi.org/10.1109/20.824439

[6] P. G. Levi and F. E. Talke, "Effect of ramp profile and spindle speed on head-disk contact during rotary load/unload," IEEE Trans. Magn., vol. 29 , no. 6, pp. 3918-3920, 1993 http://dx.doi.org/10.1109/20.281342

[7] G. Sheng and J. Zhang, "An experimental and theoretical investigation of disk damage caused by head-disk impact in loading process," IEEE Trans. Magn., vol. 37, no. 4, pp. 1863-1865, 2001.

[8] K. S. Park, J. I. Chun, and Y. Lee et al., "Improvement of loading/ unloading performance using control input position and considering disk vibration characteristics," IEEE Trans. Magn., vol. 41, no. 2, pp. 819-824, 2005.

http://dx.doi.org/10.1109/TMAG.2004.840352 